\title{
Implementing a Combination of Social and Public Health Interventions for the Effective Control of COVID-19 Pandemic
}

\author{
Saurabh RamBihariLal Shrivastava ${ }^{1}$, Prateek Saurabh Shrivastava ${ }^{2}$ \\ ${ }^{1}$ Medical Education Unit Coordinator and Member of the Institute Research Council, Department of Community Medicine, \\ Shri Sathya Sai Medical College and Research Institute, Sri Balaji Vidyapeeth - Deemed to be University, Ammapettai, \\ Nellikuppam, Chengalpet District, Tamil Nadu, India; ${ }^{2}$ Department of Community Medicine, Shri Sathya Sai Medical \\ College and Research Institute, Sri Balaji Vidyapeeth - Deemed to be University, Ammapettai, Nellikuppam, \\ Chengalpet District, Tamil Nadu, India.)
}

\begin{abstract}
The ongoing coronavirus disease-2019 (COVID-19) pandemic has gone beyond the possibility that the disease can be controlled by the solitary actions of the health sector. If we really aim to bring an end to this novel viral pandemic, we have to implement specific public health and social interventions which can either reduce or completely interrupt the probability of transmission of the disease. Amidst no availability of a vaccine or a potential therapeutic option, the scope of public health and social interventions in the effective containment of the infection is of paramount importance. However, it is important to remember that social measures cannot be there forever and they have to be gradually lifted, and at that time, the caseload will be determined by the continuation of the well proven strategies. In conclusion, in the ongoing global fight against the COVID-19 pandemic, it is extremely important that public health interventions should be implemented in close coordination with social strategies, including support from all the sections of the community to significantly minimize the risk of transmission of the infection.
\end{abstract}

\section{KEYWORDS}

COVID-19 pandemic, Public health, World Health Organization

\section{INTRODUCTION}

The ongoing coronavirus disease-2019 (COVID19) pandemic has gone beyond the possibility that the disease can be controlled by the solitary actions of the health sector. We have to accept the fact that we were not well prepared for the outbreak and even our action plan was not comprehensive enough to respond to the sudden rise in the emergence of the cases. The available estimates suggest that as on 7 June 2021, a total of 172956039 cases and 3726466 deaths has been reported worldwide, with an overall case fatality ratio of $2.15 \% .{ }^{[1]}$ In India alone, a total of 28909975 cases and 349186 deaths have been reported, which amounts to a case fatality rate of $1.2 \% .^{[1]}$ The international spread of the disease has also been very quick, as evidenced by the fact that the disease has been detected in 223 nations and territories across the world and the number continues to rise with each day. ${ }^{[1]}$

\begin{abstract}
Need of a multi-sectoral approach
In the global mission to bring an end to this novel viral pandemic, we have to implement specific public health and social interventions which can either reduce or completely interrupt the probability of transmission of the disease. ${ }^{[1,2]}$ However, this will obviously require active support from all the sections of the community, including individuals, households, communities, institutions, companies, local governments, national governments, allied sectors (viz. travel, trade, business, education, etc.) and international welfare organizations. Amidst no availability of a vaccine or a potential therapeutic
\end{abstract}

CORRESPONDING AUTHOR: Dr. Saurabh RamBihariLal Shrivastava, MD Community Medicine, FAIMER, PGDHHM, DHRM, FCS, ACME. Professor, Department of Community Medicine, Shri Sathya Sai Medical College and Research Institute, Sri Balaji Vidyapeeth (SBV) - Deemed to be University, Thiruporur - Guduvancherry Main Road, Ammapettai, Nellikuppam, Chengalpet District - 603108, Tamil Nadu, India

E Mail ID: drshrishri2008@gmail.com

ARTICLE CYCLE: Received: 29/03/2021; Revised: 07/06/2021; Accepted: 10/06/2021; Published:30/06/2021

CITATION:Shrivastava SR, Shrivastava PS. Implementing a Combination of Social and Public Health Interventions for the Effective Control of COVID-19 Pandemic. J Comp Health. 2021;9(1):38-40. 
option, the scope of public health and social interventions in the effective containment of the infection is of paramount importance..$^{[2-5]}$

In India, specific strategies have been implemented to counter the rapid rise in the number of cases and these include enforcement of lockdown in states with high caseload, restrictions have been imposed pertaining to the gathering of people in social locations, strengthening of advocacy communication and social mobilization activities by involvement of social media, improvement in the diagnostic ability by sanctioning of more laboratories, strengthening of the health care system (viz by arrangement of more number of hospital beds either in health establishments or other settings, logistics support, increase in the medications, deployment of more number of doctors and paramedical staff, etc.), intensification of research activities, and specific measures to not only augment the production of vaccines, but also to immunize all individuals in a phase-wise manner based on the risk stratification. All these measures are being supervised by the state and the central government and all initiatives are being taken to minimize the adverse impact of the disease.

\section{Population-level recommendations}

As there is conclusive evidence available that the disease is transmitted through close contacts and droplets, the importance of social and physical distancing is critical in interrupting the chain of transmission and thereby reducing the caseload. $^{[3]}$ Apart from the general recommendations, which envisages maintaining a distance of one meter or decreasing the likelihood of contact with contaminated surfaces, the specific interventions for the general population (viz. not front line workers like health care providers, police, sanitary workers, etc.) should advocate work from home, promotion of distance or e-learning, closure of non-essential facilities, and avoid going to overcrowded places. ${ }^{[3]}$ In addition, the high-risk population groups (viz. elderly and those with comorbid illnesses) should be safeguarded and restrictions should be imposed on local or national movement. ${ }^{[1,4]}$ Moreover, people should be advised to strictly stay at home and instead of physically meeting, stay connected with family members / relatives through call or social media. However, it is extremely important to understand that mere physical or social distancing will not bring the situation under control, unless it is supplemented with frequent hand washing and respiratory hygiene. ${ }^{[2]}$

In India, we started with the administration of COVID vaccines on 16 January 2021 and a total of 2 vaccines (viz. COVISHIELD and COVAXIN) are being made available for administration to the residents. ${ }^{[5,6]}$ We started the vaccination drive with immunizing health workers and elderly as they were at the highest risk to acquire the infection or suffer from disease-related complications. This was primarily done keeping in mind the dose of vaccines available with us and as the vaccine demand has increased, the production of the same has also been augmented. ${ }^{[5-7]}$ In-fact, in the process of reaching all sections of the society, the next step of the Government was to immunize all residents more than 45 years of age from 1 April 2021. Subsequently, it was decided to immunize people in the age group of 18-45 years of age from May 1 2021. As of now, we are still in shortage of vaccine and the Government has taken specific interventions to both increase the production and also had a dialogue with international leaders to promote liaison for import of effective vaccines. ${ }^{[5-7]}$ It is quite essential to realize that vaccine does offer protective immunity and all of us should get vaccinated at our turn and help the nation to fight the ongoing pandemic.

\section{Expectations from Policy Makers}

The public health interventions should be planned keeping in mind the needs of the community, which essentially include sustaining the food supply, safeguarding the income of the individuals, enhancing the flexibility of community, reducing the stress-anxiety related with the disease or loneliness and finally maintaining social connection. ${ }^{[1]}$ However, the implementation of any of the strategy should be looked for its potential merits and demerits and then only a call should be taken keeping the interests of the masses in mind. ${ }^{[1]}$ For instance, even though, we are emphasizing people to stay at home, we are not taking out their source of income by promoting work from home. At the same time. Though educational institutions have been closed, in order to ensure that the students don't suffer academically, options of e-learning have been widely explored and implemented. The people from the lower socioeconomic status have to not only safeguard themselves from the 
infection, but also have to sustain their livelihood, which was significantly interrupted during the period of lockdown. ${ }^{[9]}$ This will essentially include specific measures by the Government to safeguard the interests of these vulnerable sections of community, so that the benefits of all the planned preventive and control measures can reach them earlier. In addition, there is a definite need that additional financial investment is also done to improve their quality of life and to simultaneously reduce the risk of acquisition of infection. ${ }^{\text {[9] }}$

Moreover, while these social and public health interventions are being implemented to safeguard the safety and other interests of the general population, the public health authorities should continue to work towards an active search for cases, isolate the detected cases, perform contact tracing \& quarantine to the contacts, and finally promote research and development activities to enable the development of a drug and vaccine. ${ }^{[2,3,8]}$ However, it is important to remember that social measures cannot be there forever and they have to be gradually lifted, and at that time, the caseload will be determined by the continuation of the well proven strategies (viz. case detection, isolation, contact tracing and quarantine). ${ }^{[1,2,8]}$

\section{CONCLUSION}

In conclusion, in the ongoing global fight against

the COVID-19 pandemic, it is extremely important that public health interventions should be implemented in close coordination with social strategies, including support from all the sections of the community to significantly minimize the risk of transmission of the infection.

\section{REFERENCES}

1. World Health Organization. Weekly operational update on COVID-19 - 7 June 2021; 2021. Available from: https://www.who.int/publications/m/item/weeklyoperational-update-on-covid-19---7-june-2021 [Last accessed on 2021 Jun 8].

2. World Health Organization. 2019 Novel Coronavirus (2019-nCoV): Strategic preparedness and response plan. Geneva: WHO press; 2020. p: 1-20.

3. Mahase E. Covid-19: UK starts social distancing after new model points to 260000 potential deaths. BMJ 2020;368:m1089.

4. Shrivastava SR, Shrivastava PS. Minimizing the risk of international spread of coronavirus disease 2019 (COVID-19) outbreak by targeting travelers. J Acute Dis 2020;9:47-8.

5. Chakraborty C, Ranjan Sharma A, Bhattacharya M, Lee SS, Agoramoorthy G. COVID-19 vaccine: Challenges in developing countries and India's initiatives. Infez Med 2021;29:165-6.

6. Foy BH, Wahl B, Mehta K, Shet A, Menon GI, Britto C. Comparing COVID-19 vaccine allocation strategies in India: A mathematical modelling study. Int J Infect Dis 2021;103:431-8.

7. Chakraborty C, Agoramoorthy G. India's cost-effective COVID-19 vaccine development initiatives. Vaccine 2020;38:7883-4.

8. Salathé M, Althaus CL, Neher R, Stringhini S, Hodcroft E, Fellay J, et al. COVID-19 epidemic in Switzerland: on the importance of testing, contact tracing and isolation. Swiss Med Wkly 2020;150:w20225.

9. Mattos Dos Santos R. Isolation, social stress, low socioeconomic status and its relationship to immune response in Covid-19 pandemic context. Brain Behav Immun Health 2020;7:100103. 